\title{
Effect of Dietary Casein, Fats and Saline on the Atheromatous Lesions of the Aorta, Coronary Arteries and Renal Small Arteries in Rats
}

\author{
KôIchi Nakadate \\ School of Liberal Arts and Sciences, Iwate Medical University, \\ Morioka
}

\begin{abstract}
Nakadate, K. Effect of Dietary Casein, Fats and Saline on the Atheromatous Lesions of the Aorta, Coronary Arteries and Renal Small Arteries in Rats. Tohoku J. exp. Med., 1973, $111(2), 157-174$ - Male albino rats of the Donryu strain weighing $120 \mathrm{~g}$ were fed high-fat $(40 \%)$ atherogenic diets with two casein levels for 16 weeks. Either hydrogenated kapok oil or butter fat was used in the diet. One $\%$ saline or tap water was offered as drinking water. The rats fed high casein $(31 \%)$ diets showed remarkably high growth, and their serum cholesterol levels were about one half of those of low casein $(11 \%)$ groups. One $\%$ saline increased slightly the serum cholesterol levels. Fatty lesions of the arteries in the heart, kidneys, aortae, and renal glomeruli of rats fed high casein diets were milder compared to those of low casein groups, and all the lesions except for those of renal glomeruli were potentiated by the saline administration. The lesions of coronary arteries, cardiac muscles, and glomeruli of the hydrogenated oil group were severer than those of the butter fat group although serum cholesterol level of the former was somewhat lower than the latter. However, atheromatous lesion of aortae was severer in the butter fat group. No intimal lesion of the arteries was observed in kidneys and the lipids in media were seen along adventitia. _ a atherosclerosis; casein; fat source; saline
\end{abstract}

It has been about twenty years since the histological lesions comparable to human atherosclerosis were produced in rats by dietary means (Hartroft et al. 1952; Wissler et al. 1954). Several diet compositions have been proposed as causative agents to produce the lesions and some knowledge has accumulated about the dietary factors which are considered to be related with the arterial lesions (Thomas et al. 1959; Gresham and Howard 1960).

A study on the relation between the incidence or development of atherosclerosis and certain nutritional elements or general nutritional condition of animals is one of the most interesting problems in the field of nutritional sciences. It will be quite important to find ways to lower the incidence of arterial lesions and to suppress the development by dietary means.

Received for publication, March 2, 1973.

Presented at the 25th Annual Meeting of the Japanese Society of Food and Nutrition, Tokyo, June 9, 1971 and at the 26th Annual Meeting, Tokushima City, April 29, 1972 . 
It appears now established that the development of atherosclerosis is related with the level of serum cholesterol (Kritchevsky 1962). Many interesting studies have been reported concerning the effect of dietary components, namely, quantity and quality of protein and kinds of fat, on the level of serum cholesterol. However, only a few studies of experimental atherosclerosis have been conducted from a nutritional stand-point.

The present paper describes the nutritional and histopathological effects which were induced by the modification of some constituents of the atherogenic diet on the serum and liver cholesterol levels, and on the histological changes occurring in the cardiovascular and renal vascular systems of rats.

\section{Materials and Methods}

\section{Animals and diets}

Male albino rats of the Donryu strain were used and their average weight was 120 g. The experimental diets were high-fat ones containing cholesterol and cholic acid. They were similar to that used initially by Thomas and Hartroft (1959), but propylthiouracil was not added. Two kinds of dietary fat were used. The one was a mixture of 19 parts of hydrogenated kapok oil and one part of soybean oil (hereafter referred to as the hydrogenated oil) and the other was non-salted butter fat. Soybean oil was added to the hydrogenated kapok oil so as to make the linoleic acid content of the mixture comparable to that of butter fat. The chemical properties of the fats are shown in Table 2. Two casein levels were employed and they were $11 \%$ and $31 \%$, respectively. The difference between two casein contents was compensated by sucrose. The animals were offered tap water or $1 \%$ saline as drinking water. As a result, four experimental groups were established as presented in Table 1 .

The rats were housed individually in the eages with wire screen bottoms. Each of the experimental groups had 8-9 animals at the beginning and the duration of the experiment was 16 weeks. Diet and water were offered ad libitum. Diet intake of each animal was recorded daily and weight gains were measured weekly.

\section{Histological investigation}

At the end of the experiment all surviving rats were killed by bleeding from cervical vessels under ether anesthesia. Immediately animals were autopsied and the organs such as liver, heart, aorta and kidneys were removed. They were examined grossly, weighed and fixed in $10 \%$ formalin. The lower half of the right liver lobe was stored at $-20^{\circ} \mathrm{C}$ for lipid analysis.

After fixation, tissue blocks were obtained from the heart, aorta and kidneys by the following method. Frozen sections were prepared from the tissue blocks and paraffin sections were obtained from the remainder of the blocks in the routine manner.

As indicated in Fig. 1, the heart was cut across 1-2 mm under the right atrium. Two pieces of cross-cut tissue blocks were prepared from the lower part. From the upper part, a perpendicular block was obtained, which contained the orifice of aorta and parts of each atrium. A part of the ascending aorta was included in the perpendicular tissue block.

The aorta was divided into three portions, that is, arcuate, thoracic, and abdominal ones. Longitudinal histological sections of each portion were then prepared by the method reported by the author et al. (1973).

From each kidney a transverse tissue block which contained hilus renalis was prepared.

Frozen sections were subjected to Sudan III, nile blue, Smith-Dietrich stains and Schultz's sterol reaction method. Hematoxylin and eosin, Van Gieson, PAS, and Weigert's elastin stains were applied to the paraffin sections. 
TaBLE 1. Composition of experimental diet (\%)

\begin{tabular}{lcccc}
\hline & \multicolumn{5}{c}{ Dietary group } \\
\cline { 2 - 5 } Ingredient & I & II & III & IV \\
\hline Casein* & 31 & 31 & 11 & 11 \\
Kapok-Soybean mixture $\dagger$ & 40 & 40 & 40 & - \\
Non-salted butter & - & - & - & 40 \\
Sucrose & 10 & 10 & 30 & 30 \\
Cellulose & 5.8 & 5.8 & 5.8 & 5.8 \\
Salt mixture§ & 4.0 & 4.0 & 4.0 & 4.0 \\
Vitamin mixture// & 2.0 & 2.0 & 2.0 & 2.0 \\
Choline-HCl & 0.2 & 0.2 & 0.2 & 0.2 \\
Cholesterol II & 5.0 & 5.0 & 5.0 & 5.0 \\
Cholic acid I & 2.0 & 2.0 & 2.0 & 2.0 \\
Drinking water & Tap water & $1 \%$ saline & $1 \%$ saline & $1 \%$ saline \\
\hline
\end{tabular}

* MOE Hydrochloric casein, 30-40 mesh, from the MOE Dairying Co., Australia. The riboflavin content was $0.166 \mathrm{mg}$ per $100 \mathrm{~g}$.

$\dagger$ Mixture of nineteen parts of hydrogenated kapok oil and a part of commercial soybean oil. Detailed information on the mixture is presented in Table 2.

$\ddagger$ Pulp-Flock white, from the Sanyo Pulp Co., Tokyo.

$\S$ This was identical with Harper's mixture (Harper, A.E. (1959) J. Nutr., 68, 405).

// Vitamin mixture used was prepared as follows: commercial vitamin mixture for animal experiment (Tanabe Amino Acid Research Foundation, Osaka) and "Vitaplex" powder for medical use (Tokyo Tanabe Co., Tokyo) were mixed in equal portion, and in addition, suitable amounts of pyridoxine $\cdot \mathrm{HCl}$, ascorbic acid, $\alpha$-tocopheryl acetate, menadione, $\mathrm{Ca}$ pantothenate, $\rho$-aminobenzoic acid were added and mixed thoroughly. The resulting vitamin mixture contained: vitamin A, 2500 units; vitamin D, 200 units; and (in $\mathrm{mg}$ ) $a$-tocopheryl acetate, 10 ; ascorbic acid, 90 ; niacin, 12.9; riboflavin, 3.6; pyridoxine. $\mathrm{HCl}, 2.0$; thiamine $\cdot \mathrm{HCl}, 2.6$; $\mathrm{Ca}$ pantothenate, 6.0 ; biotin, 0.04 ; folic acid, 0.52 ; cyanocobalamin, 0.003 ; inositol, 11.8; menadione, $4.5 ; \rho$-aminobenzoic acid, 10.0; and lactose to make 2 grams.

I Crystalline cholesterol and cholic acid were furnished by the Eisai Co., Tokyo.

TABLE 2. Properties of oil and fat used

\begin{tabular}{lccc}
\hline \multicolumn{1}{c}{ Oil and fat* } & Iodine value & $\begin{array}{c}\text { Saturated fatty } \\
\text { acid }(\%)\end{array}$ & $\begin{array}{c}\text { Linoleic acid } \\
(\%)\end{array}$ \\
\hline Soybean oil & 133 & 13.2 & 50.2 \\
Non-salted butter & 24 & 57.8 & 2.1 \\
Hydrogenated kapok oil & 69 & 39.4 & 0.0 \\
Kapok-Soybean mixture & 72 & 38.1 & 2.5 \\
\hline
\end{tabular}

* The percentages of fatty acids in soybean oil and butter fat were cited from pages 27 and 30 in reference 5. Hydrogenated kapok oil was supplied by the Asahi Denka Kogyo Co., Tokyo. No antioxidant was contained. Melting point of the material was $36.2^{\circ} \mathrm{C}$. Analytical data of fatty acid composition were also provided by their laboratory. Data on the mixture of hydrogenated kapok oil and soybean oil were calculated according to the ratio $[19: 1]$ of the original oils.

\section{Chemical analysis}

Blood depleted from cervical vessels was collected in a small centrifuge tube and kept overnight at room temperature to clot. The serum was collected by centrifugation and frozen at $-20^{\circ} \mathrm{C}$. Total serum cholesterol was measured by the method of Pearson with 


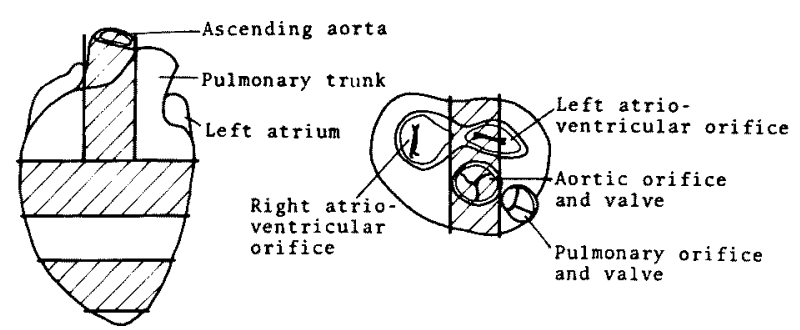

Fig. 1. Preparing tissue blocks of rat heart. Shaded regions were used for histological examinations.

the modification for micro-technique (Shibata and Sasaki 1967). Total liver lipids were extracted by the method of Folch et al. (1957). An aliquot of the extract was dried and the weight of the residue was recorded as total lipids. Total liver cholesterol was determined by applying the same method used for serum to another aliquot.

Iodine values of the fats used were determined by the method of Weijs (reference 5 1969).

\section{RESUlts}

Growth of rats

As shown in Fig. 2, weight gains of rats fed low casein diets (11\%; groups III and IV) were remarkably lower than those of rats fed high casein diets (31\%; groups I and II). The growth of rats fed the hydrogenated oil diet (group III) exceeded that of those fed the butter fat diet (group IV) in the early stage of the experiment. However, the situation was reversed in the sixth week and there-

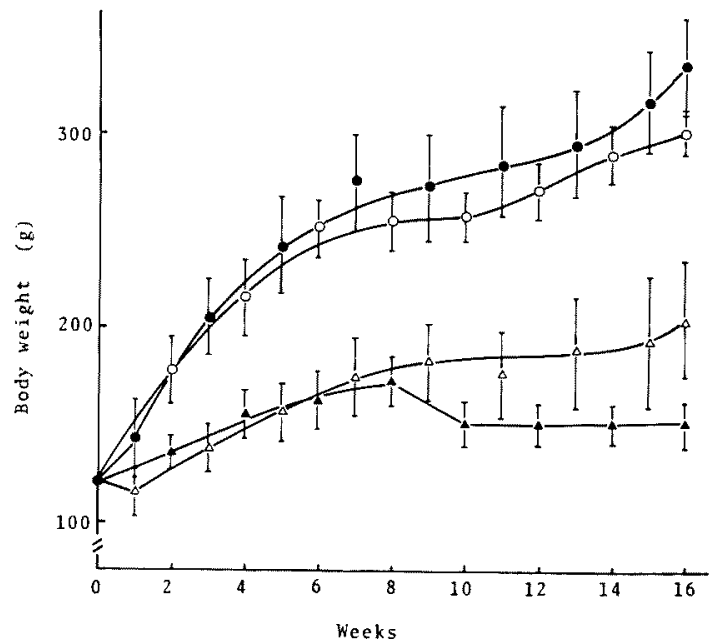

Fig. 2. Weight gains of rats.

- - Group I; high casein, tap water. o—o Group II; high casein, 1\% saline. Group III; low casein, 1\% saline. $\triangle \longrightarrow \Delta$ Group IV; low casein, $1 \%$ saline, butter. The vertical line indicates a standard deviation. 
after the difference in body weights steadily increased. The growth of rats offered saline was slightly inferior to that of those given tap water.

Average diet intakes during 61 days, from the 30th to 90 th day of the experiment, were shown in Table 3. The largest amount of diet was consumed by rats in group IV followed by groups I, II and III in decreasing order. The weight gains of rats were not proportional to their diet intakes but greatly affected by the amount of casein in the diets.

Although the volume of drinking water consumed was not measured, the rats offered saline drank so much that the volume of saline consumed was more than twice that of tap water.

At the seventh week of the experiment, several rats in the groups fed low casein diets (groups III and IV) began to lose most of the hair from their backs and flanks. One rat in group I suffered from loss of hair 12 weeks later but none in group II did.

Three rats died during the experiment. Two of them suffered from pulmonary infections, but the real cause of their death was not clear in every case.

TABLE 3. Number of rats, body weight and diet intake

\begin{tabular}{|c|c|c|c|c|c|c|c|}
\hline \multirow[b]{2}{*}{ Group } & \multirow[b]{2}{*}{ Diet } & \multicolumn{3}{|c|}{ Number of rats } & \multicolumn{2}{|c|}{ Body weight $(g)$} & \multirow{2}{*}{$\begin{array}{c}\text { Diet intake* } \\
\text { (g/rat/day) }\end{array}$} \\
\hline & & Initial & Final & $\begin{array}{c}\text { Loss of } \\
\text { hair }\end{array}$ & Initial & Final & \\
\hline I & $\begin{array}{l}\text { High casein, tap } \\
\text { water }\end{array}$ & 8 & 8 & 1 & $119 \pm 16 \dagger$ & $336 \pm 26$ & $14.1 \pm 1.4$ \\
\hline II & High casein, saline & 8 & 7 & 0 & $119 \pm 15$ & $300 \pm 13$ & $12.7 \pm 1.2$ \\
\hline III & Low casein, saline & 8 & 8 & 4 & $118 \pm 9$ & $151 \pm 13$ & $11.8 \pm 1.3$ \\
\hline IV & $\begin{array}{l}\text { Low casein, saline, } \\
\text { butter }\end{array}$ & 9 & 7 & 4 & $119 \pm 15$ & $206 \pm 30$ & $16.2 \pm 1.4$ \\
\hline
\end{tabular}

Male rats (Donryu albinos) were housed individually in wire-bottom cages. Diet and water were given ad libitum. Duration of experiment was 16 weeks.

* Mean values of diet intake for the period of 61 days, that is, from the 30th to 90th day after initiation of experiment.

$\dagger$ Mean value \pm standard deviation.

\section{Cholesterol in serum and liver}

As shown in Table 4, the concentrations of total serum cholesterol in rats fed high casein diets were less than half of those fed low casein diets. However, even the high casein rats showed a three-fold increase in serum cholesterol level over that of the control animals fed the stock diet and clearly they were suffering from hypercholesterolemia. The serum cholesterol level of the animals showed a trend to increase when butter fat was substituted for the hydrogenated oil or saline for tap water, but this was not statistically significant in both cases.

Total liver lipids in the high casein rats were, as shown in Table 4, clearly lower than in the animals fed low casein diets. However as compared to the control rats, total liver lipids even of the high casein rats were ten times as much as the 
TABLE 4. Total lipid and total cholesterol concentrations in serum and liver, and liver weights

\begin{tabular}{|c|c|c|c|c|c|c|}
\hline \multirow[b]{2}{*}{ Group } & \multirow[b]{2}{*}{ Diet } & \multirow[b]{2}{*}{$\begin{array}{c}\text { Number } \\
\text { of } \\
\text { rats }\end{array}$} & \multirow{2}{*}{$\begin{array}{c}\text { Serum } \\
\begin{array}{c}\text { Total } \\
\text { cholesterol } \\
(\mathrm{mg} / 100 \mathrm{ml})\end{array}\end{array}$} & \multicolumn{3}{|c|}{ Liver } \\
\hline & & & & $\begin{array}{l}\text { Total } \\
\text { lipids } \\
\text { (mg/g) }\end{array}$ & $\begin{array}{c}\text { Total } \\
\text { cholesterol } \\
\text { (mg/g) }\end{array}$ & $\begin{array}{c}\text { Weight } \\
\text { (g/100 g } \\
\text { body weight) }\end{array}$ \\
\hline $\mathbf{I}$ & $\begin{array}{l}\text { High casein, tap } \\
\text { water }\end{array}$ & 7 & $270 \pm 38^{*}$ & $306 \pm 22$ & $147 \pm 13$ & $8.2 \pm 0.8$ \\
\hline II & High casein, saline & 7 & $309 \pm 70$ & $337 \pm 30$ & $168 \pm 16 \dagger$ & $8.9 \pm 0.7$ \\
\hline III & Low casein, saline & 8 & $637 \pm 158$ & $457 \pm 25$ & $237 \pm 14$ & $14.6 \pm 2.1$ \\
\hline IV $\mathrm{I}$ & $\begin{array}{l}\text { Low casein, saline, } \\
\text { butter }\end{array}$ & 7 & $744 \pm 181$ & $461 \pm 27$ & $258 \pm 18+$ & $15.0 \pm 1.5$ \\
\hline \multicolumn{2}{|c|}{ Control } & 8 & $94 \pm 27$ & $29 \pm 3$ & & $2.8 \pm 0.2$ \\
\hline
\end{tabular}

* Mean value \pm standard deviation.

$\uparrow$ Difference of the mean values between groups $\mathrm{I}$ and II is significant, $\mathrm{P}<0.05$.

‡ Difference of the mean values between groups III and IV is significant, $\mathrm{P}<0.05$.

value of the control rats and their livers were apparently fatty. Total liver lipids showed a trend to a slight increase in rats offered saline, but the increase was not significant. Although the mean diet intake of rats fed butter fat considerably exceeded that of those fed the hydrogenated oil (Table 3), the increase of the total liver lipids was slight.

The total liver cholesterol of rats in all the experimental groups amounted to about one half of the total liver lipids. Like the total liver lipids, liver cholesterol levels of the high casein rats were significantly lower than those of the low casein rats. When $1 \%$ saline was given to rats instead of tap water the liver cholesterol level was somewhat elevated, and the increase was statistically significant at the $5 \%$ level. Liver cholesterol level of the butter fat rats was only slightly higher than that of rats fed the hydrogenated oil diet but the difference was also statistically significant at the $5 \%$ level.

\section{Histological findings of some organs}

Heart: Fatty lesions of the heart were found at the aortic valves, coronary arteries, and cardiac muscles.

As shown in Figs. 3 and 4, the atheromatous lesions in the walls of coronary arteries were characterized by the thickening of intima and media and the lipid deposition in them, accompanied by the narrowing of the arterial lumen. These lesions were mainly seen in the sections prepared from the perpendicularly cut blocks from the upper part of the heart. They occurred mostly in small arteries distributed in muscle layers which composed the basal portion of the heart, especially in the upper part of the interventricular septum and the left ventricular wall. However, these abnormalities were scarcely seen in the arteries in the right ventricular wall.

There were few lesions in the walls of larger coronary arteries, but these arterial lumens were frequently occluded in various degrees with blood cells and 


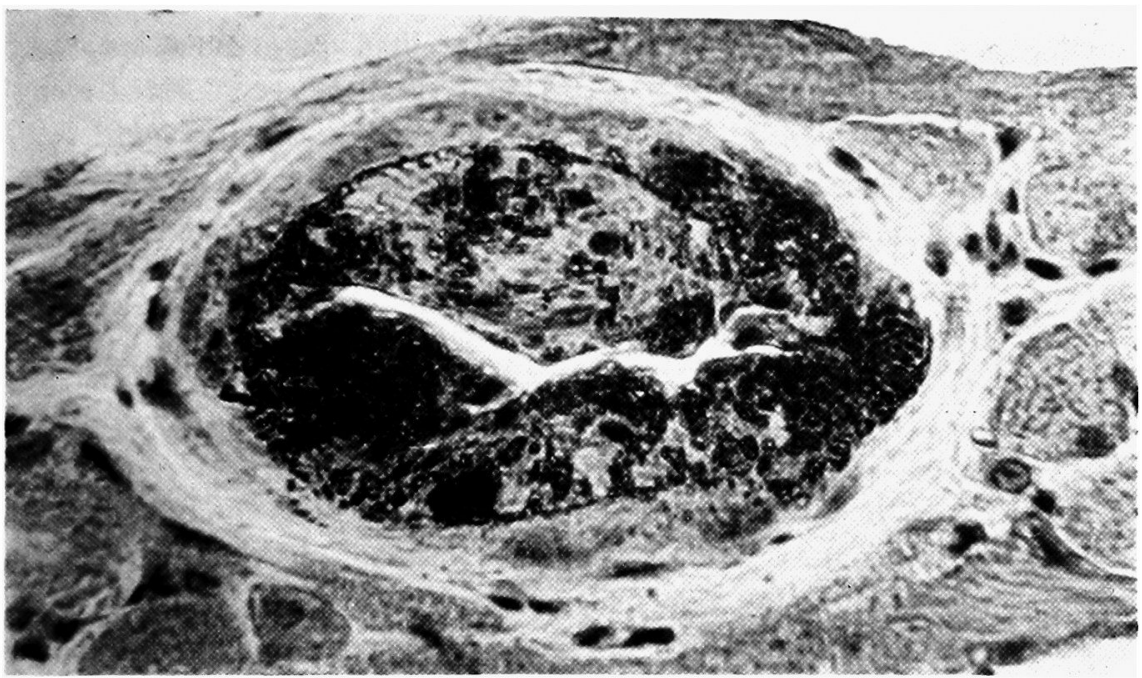

Fig. 3. Atheromatous lesion of relatively small coronary artery in upper part of left ventricular wall. Intima shows proliferative thickening and lipid deposition, accompanied by remarkable narrowing of arterial lumen. A rat in group III (low casein, $1 \%$ saline). Sudan III and hematoxylin, $\times 600$.

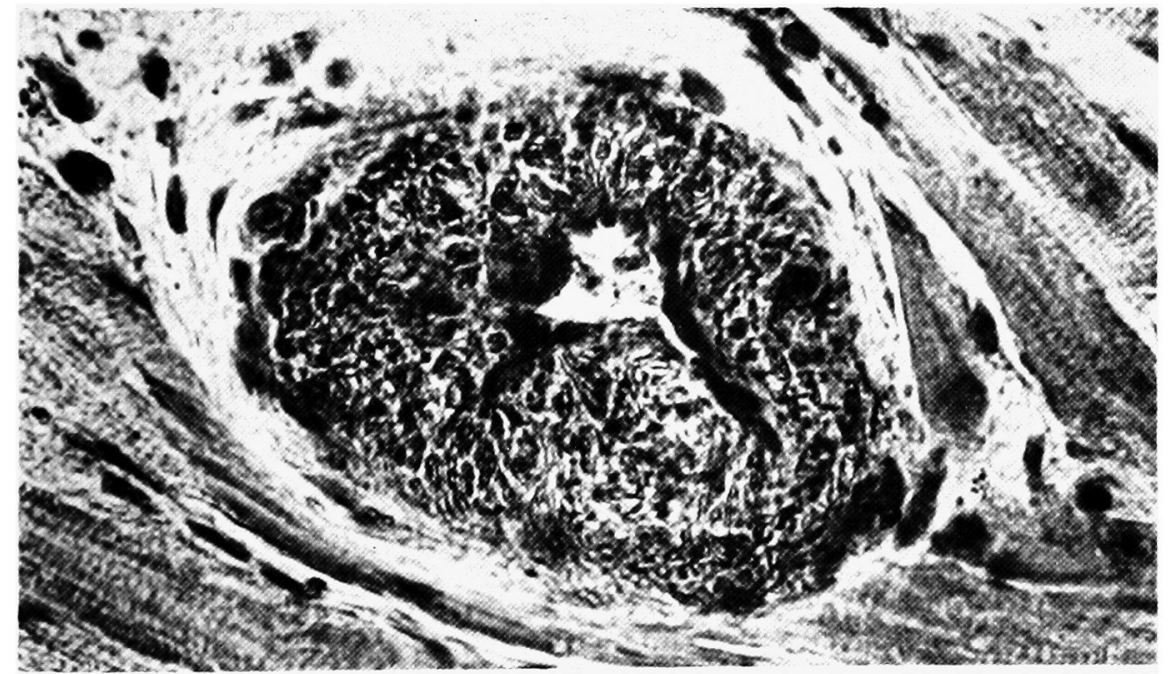

Fig. 4. Atheromatous lesion of relatively small coronary artery in upper part of left ventricular wall. Severe lipid deposition occurs in arterial wall and results in remarkable narrowing of lumen. A rat in group III (low casein, 1\% saline). Sudan III and hematoxylin, $\times 600$.

plasma materials. When the control rats were killed by bleeding the lumens of their coronary arteries and veins were usually empty. Although blood cells occasionally remained in the veins no plasma materials were observed. 
All rats fed the experimental diets showed lipid deposition in their cardiac muscles in various degrees. The distribution of lipids was somewhat irregular and the sizes of lipid droplets were varied, and the droplets appeared along the muscle fibers.

The lipids which appeared in various part of the heart were all positive to Schultz's method showing these to be composed mostly of cholesterol and its esters.

Aorta: The histological changes of aorta were classified into the following four groups, i.e. lipid deposition in the cartilaginous tissue at the initial portion of aorta, proliferative thickening of intima with and without lipid deposition, lipid deposition in media and also in adventitia.

The thickening of intima and the lipid deposition in media were more pronounced in thoracic aorta. The thickening of intima was especially conspicuous around the orifices of arteries branching off from the aorta (Fig. 12). On the other hand, the lipid deposition in adventitia was limited chiefly to abdominal aorta and scarcely seen in the thoracic one.

As the lipids in aorta were all positive to Schultz's method, it was clear that these consisted mainly of cholesterol and its esters.

Fig. 5 shows an example of severe lipid deposition seen in the cartilaginous tissue at the initial portion of aorta. The tissue was dilated and occupied mostly by the large cells containing lipids. A few cells which contained PAS positive granules were also seen in the tissue. The lesion was seen in nearly all the rats in every experimental group.

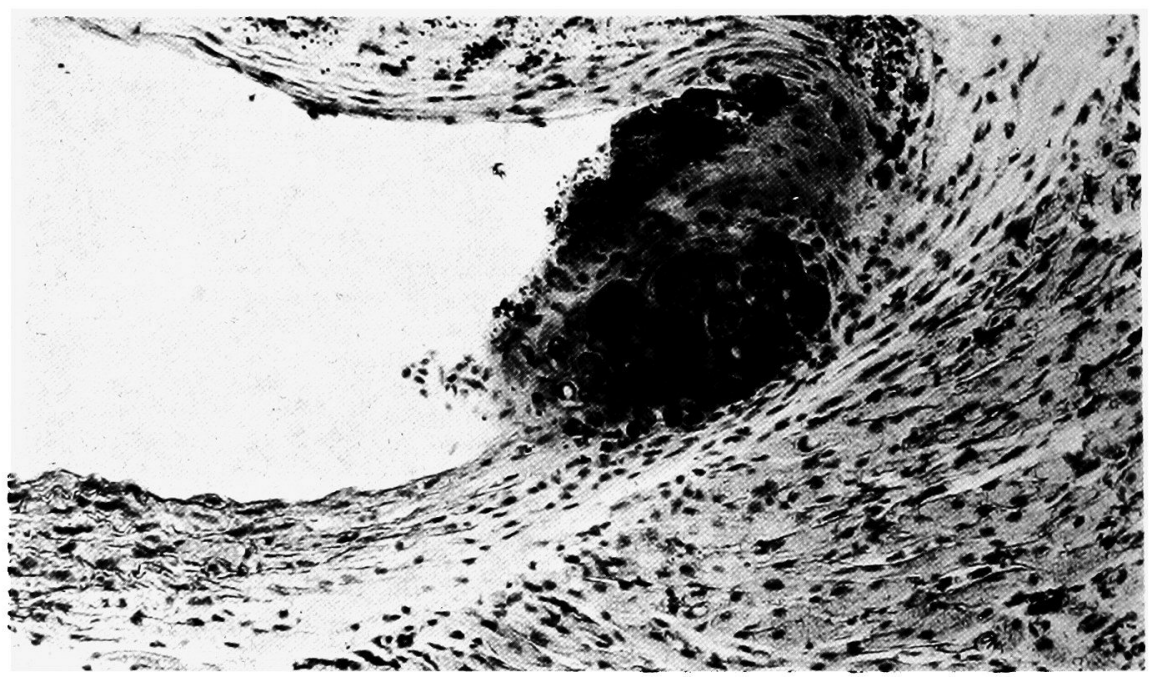

Fig. 5. Lipid deposition in cartilaginous tissue at initial portion of aorta. The tissue is dilated and the cells in it are distended by the lipid deposition. Upper; a part of aortic valve. Lower; initial portion of aorta. A rat in group III (low casein, 1\% saline). Sudan III and hematoxylin, $\times 150$. 
Thickened intima formed diffusely marginated plaques of various sizes and their surfaces were uneven. As seen in Fig. 6, the plaques generally contained much lipids but some of them were free from lipids. Moreover the plaques contained abundant necrotic debris and sparsely multilayered nuclei. Many of the nuclei were spindle-shaped, and some nuclei were swollen and had ghost outlines indicating degenerative changes (Fig. 7). The plaques were more deeply stained with eosin than the medial muscle cells and also they were stained yellow with Van Gieson stain. Occasionally the plaques contained a small amount of PAS positive granules but they did not contain any Weigert's elastin stain positive substances.

The lipids in the media distributed more widely in the inner media. When the lipid deposition was still slight, a line of the fine droplets of lipids was seen close to the each elastic lamina. With the accelerated lesion, the lipid droplets became larger in size and increased in number and they spread throughout the smooth muscle layer between the elastic laminae. Although severe lipid deposition

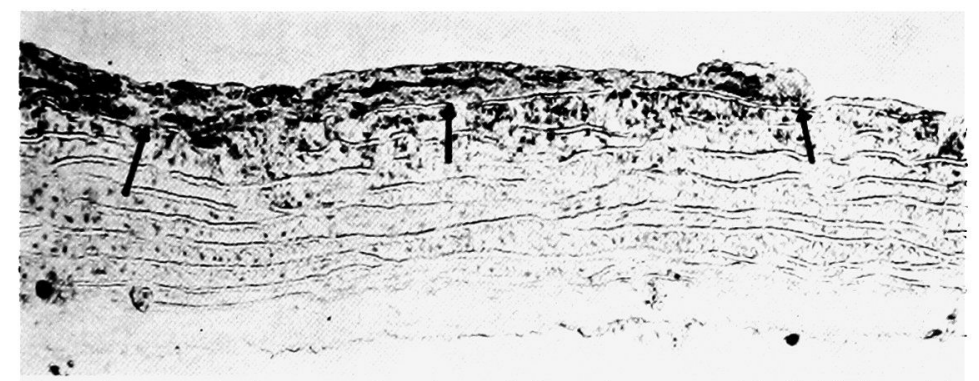

Fig. 6. Proliferative thickening of intima of thoracic aorta with lipid deposition. Thickened region is indicated by arrows. A rat in group IV (low casein, 1\% saline, butter). Sudan III and hematoxylin, $\times \mathbf{1 5 0}$.

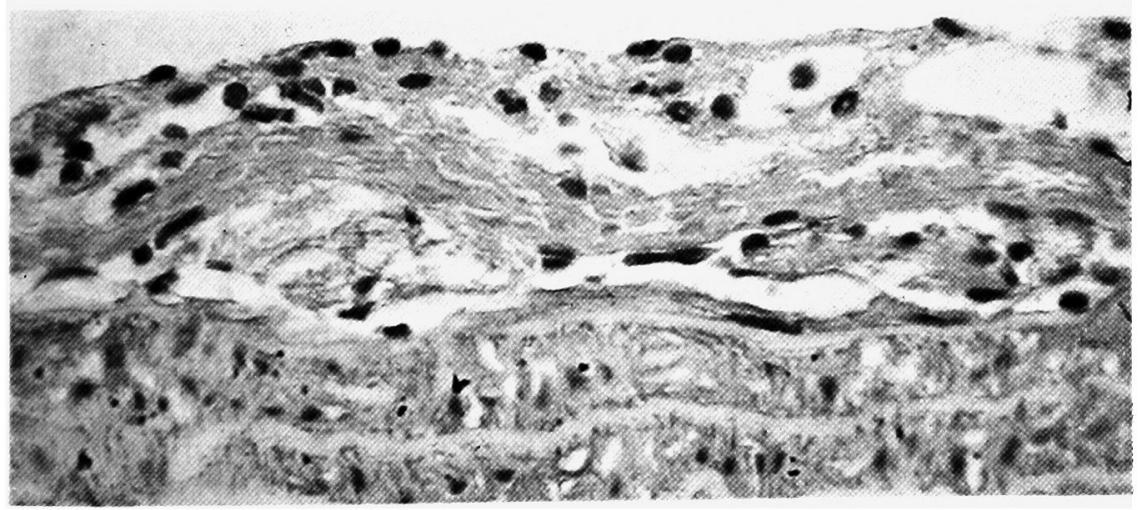

Fig. 7. Thickened intima of thoracic aorta. Substances indicating necrotic degeneration and lipid deposition are seen. A rat in group IV (low casein, 1\% saline, butter). Van Gieson stain, $\times 500$. 


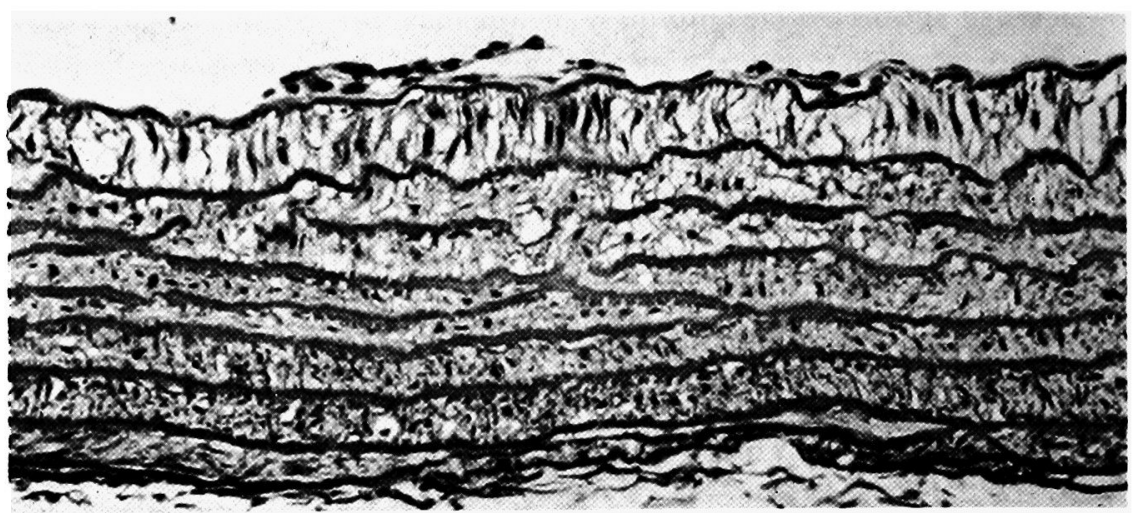

Fig. 8. Lipid deposition in media of thoracic aorta. Smooth muscle cells are deformed and vacuolated. Distance between adjacent elastic laminae is enlarged and laminae are often ruptured. A rat in group IV (low casein, 1\% saline, butter). Weigert's elastin stain, $\times 300$.

in media tended to occur in rats afflicted with pronounced intimal thickening, these two kinds of lesions were not necessarily seen in the same portion of aorta. When a large amount of lipids appeared in the adventitia of the abdominal aorta, the lipid deposition in media was often observed in its outer part which was in contact with the lipid-infiltrated adventitia (Fig. 12). Smooth muscle cells of the lipid-infiltrated media were distended and vacuolated. The distance between adjacent elastic laminae was enlarged and laminae were often ruptured (Fig. 8). However, the substances positive to PAS or Weigert's elastin stains were not recognized. Also no substance stained red with Van Gieson stain was found.

Kidneys: The conspicuous lipid deposition in the glomerular capillary loop was observed in nearly all kidneys of the experimental rats. The lipid droplets of various sizes were assumed to be in the lumens of the glomerular capillaries, affluent and effluent arteries or taken up by their endothelial cells. The lipid deposition in the glomerular capillaries was often severer near the vascular pole. However, there were no any lipid droplets in the Bowman's space and its epithelium or in the lumen and the epithelium of the urinary tubules.

The lipid deposition was often found in vasa recta of the medullary part. It was assumed that the lipid droplets, as in the case of the glomerular capillary loop, occluded the lumen or were taken up by the endothelial cells (Fig. 10).

Lipids were observed in the walls of arcuate arteries and other small arteries of kidneys. The lipids were without exception extremely abundant at its outer media and they were clearly demarcated by the external elastic lamina from its adventitia which did not contain any lipids (Fig. 11). This made a remarkable contrast with the coronary arteries or aorta where the lipids appeared mostly in the intima and inner media. Another remarkable feature was the total absence of proliferative thickening and lipid deposition in intima, both of which were commonly observed in the coronary arteries and aorta. The blood cells and plasma 


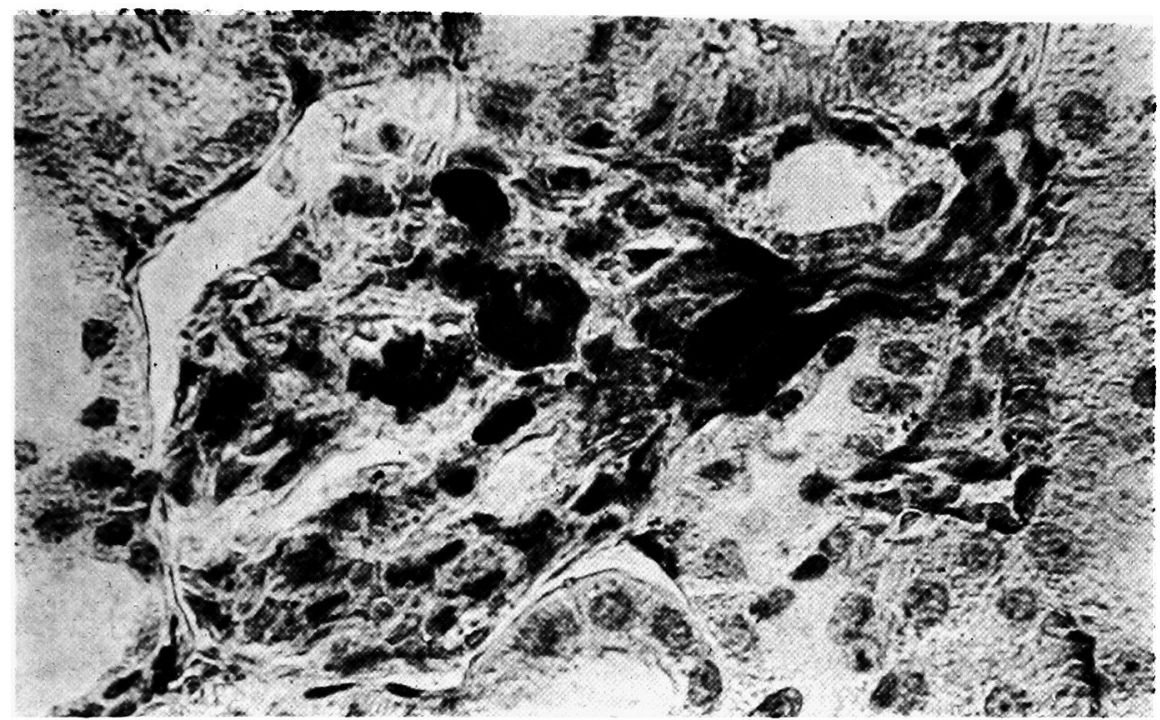

Fig. 9. Lipid deposition in glomerular capillary loop. It is often severer near vascular pole. No lipid droplets are seen in Bowman's space. A rat in group III (low casein, $1 \%$ saline). Sudan III and hematoxylin, green filter, $\times 600$.

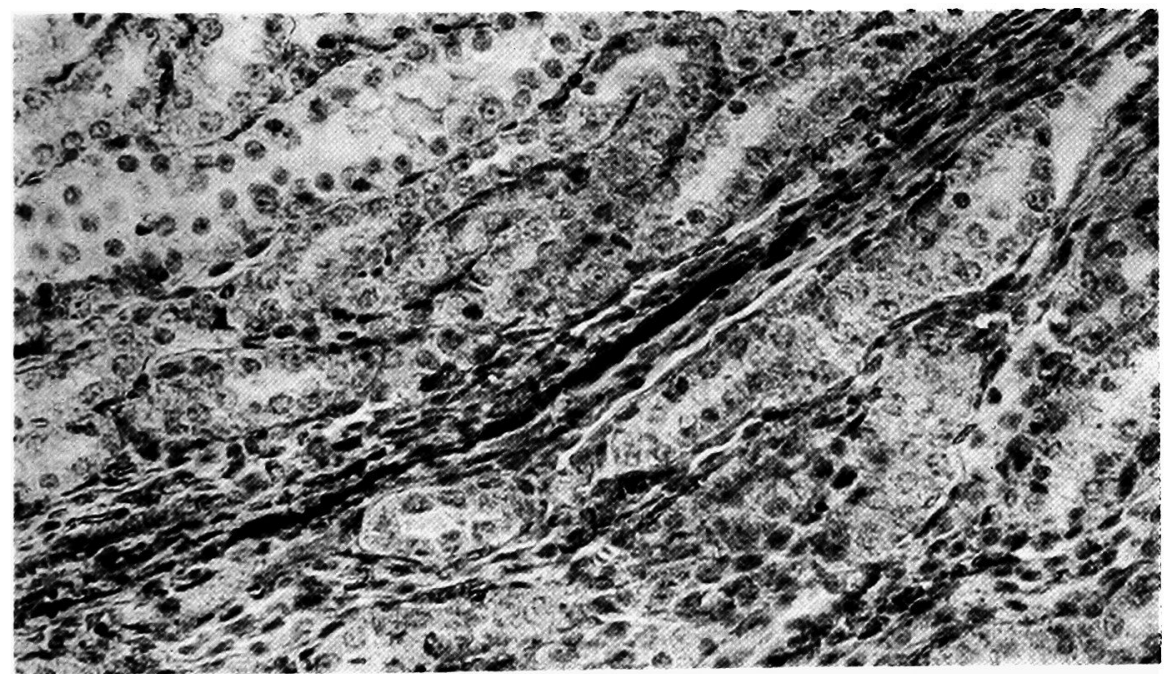

Fig. 10. Lipid deposition in vasa recta of medullary part of kidney. A rat in group III (low casein, $1 \%$ saline). Sudan III and hematoxylin, $\times 300$.

materials were also observed in the arterial lumens. The plasma materials seemed to adhere strongly to the intimal surface.

The lipids in the kidneys were positive to Schultz's method, therefore it was clear that they consisted mainly of cholesterol and its esters as in the case of the heart and aorta. 


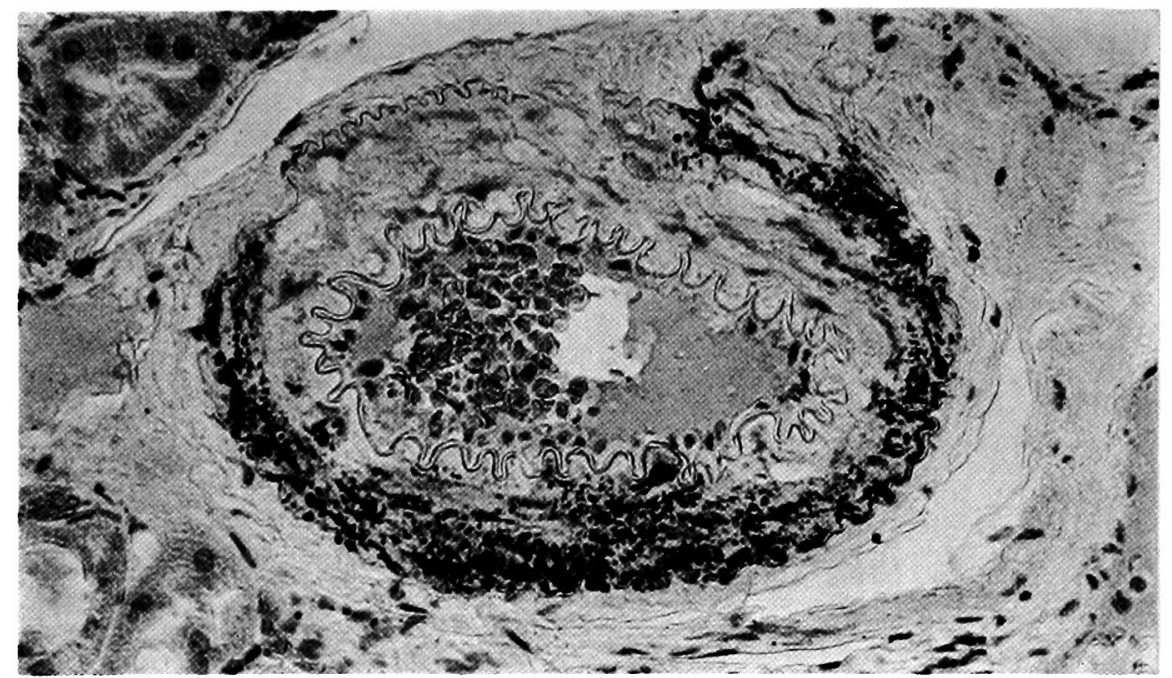

Fig. 11. Lipid deposition in wall of renal small artery. Lipids in arterial wall are abundant at its outer media and they are clearly demarcated by external elastic lamina from its adventitia which does not contain any lipids. A rat in group III (low casein, 1\% saline). Sudan III and hematoxylin, $\times 300$.

\section{The correlation between the dietary treatment and the histological changes}

Heart and kidneys: There were no essential differences in the histological changes of the two organs among the different dietary groups but remarkable differences were recognized in severity. Among the histological changes in the heart and kidneys, the following four were estimated for their severity: fatty lesions in the walls of coronary arteries and renal small arteries, fatty lesions of cardiac muscles and renal glomeruli. The estimated severity of the four changes was shown in Table 5, in which the severity of each lesion was graded from 0 [no lipid deposition] to 4 [severest lipid deposition].

The degrees of the four kinds of lesions of the high casein groups I and II were considerably smaller than those of the low casein groups III and IV. Substitution of $1 \%$ saline for tap water resulted in a slight increase in the lesions in the arteries of both organs. On the other hand, the fatty lesions of these small arteries and glomeruli were somewhat alleviated by substituting butter fat for the hydrogenated oil in spite of the slight elevation of serum cholesterol.

The fatty lesion of cardiac muscles was the severest in group III rats which were fed the low casein and hydrogenated oil diet, but moderate lesion was also seen in the heart of the high casein rats. There was no good correlation between the serum cholesterol level and the severity of the lesion in cardiac muscles. The fatty lesion of cardiac muscles, like that of small arteries of the heart and kidneys, was potentiated by the saline administration but attenuated by the substitution of butter fat for the hydrogenated oil. 
TABLE 5. Fatty lesions of heart and kidneys

\begin{tabular}{|c|c|c|c|c|c|c|c|}
\hline \multirow[b]{2}{*}{ Group } & \multirow[b]{2}{*}{ Diet } & \multirow[b]{2}{*}{$\begin{array}{c}\text { Number } \\
\text { of } \\
\text { rats }\end{array}$} & \multirow[b]{2}{*}{$\begin{array}{c}\text { Degree } \\
\text { of lipid } \\
\text { deposition* }\end{array}$} & \multicolumn{4}{|c|}{ Number of rats for each degree of severity } \\
\hline & & & & $\begin{array}{l}\text { Wall of } \\
\text { small } \\
\text { coronary } \\
\text { artery }\end{array}$ & $\begin{array}{l}\text { Cardiac } \\
\text { muscle }\end{array}$ & $\begin{array}{c}\text { Renal } \\
\text { glomerulus }\end{array}$ & $\begin{array}{l}\text { Wall of } \\
\text { renal small } \\
\text { artery }\end{array}$ \\
\hline I & $\begin{array}{l}\text { High casein, tap } \\
\text { water }\end{array}$ & & $\left\{\begin{array}{l}0 \\
1 \\
2 \\
3 \\
4\end{array}\right.$ & $\begin{array}{l}2 \\
2 \\
2 \\
1 \\
0\end{array}$ & $\begin{array}{l}1 \\
2 \\
0 \\
2 \\
2\end{array}$ & $\begin{array}{l}4 \\
2 \\
1 \\
0 \\
0\end{array}$ & $\begin{array}{l}4 \\
2 \\
1 \\
0 \\
0\end{array}$ \\
\hline$\Pi$ & High casein, saline & & $\left\{\begin{array}{l}0 \\
1 \\
2 \\
3 \\
4\end{array}\right.$ & $\begin{array}{l}1 \\
0 \\
5 \\
1 \\
0\end{array}$ & $\begin{array}{l}0 \\
0 \\
2 \\
5 \\
0\end{array}$ & $\begin{array}{l}5 \\
2 \\
0 \\
0 \\
0\end{array}$ & $\begin{array}{l}0 \\
3 \\
4 \\
0 \\
0\end{array}$ \\
\hline III & Low casein, saline & 8 & $\left\{\begin{array}{l}0 \\
1 \\
2 \\
3 \\
4\end{array}\right.$ & $\begin{array}{l}0 \\
0 \\
0 \\
2 \\
6\end{array}$ & $\begin{array}{l}0 \\
1 \\
2 \\
0 \\
5\end{array}$ & $\begin{array}{l}0 \\
0 \\
2 \\
2 \\
4\end{array}$ & $\begin{array}{l}1 \\
2 \\
1 \\
3 \\
1\end{array}$ \\
\hline IV & $\begin{array}{l}\text { Low casein, saline, } \\
\text { butter }\end{array}$ & 8 & $\left\{\begin{array}{l}0 \\
1 \\
2 \\
3 \\
4\end{array}\right.$ & $\begin{array}{l}0 \\
0 \\
2 \\
1 \\
5\end{array}$ & $\begin{array}{l}0 \\
1 \\
4 \\
3 \\
0\end{array}$ & $\begin{array}{l}0 \\
0 \\
4 \\
3 \\
1\end{array}$ & $\begin{array}{l}1 \\
2 \\
3 \\
1 \\
1\end{array}$ \\
\hline
\end{tabular}

* Severity of fatty lesions in each organ was graded from 0 [no lipid deposition] to 4 [severest lipid deposition] and numbers of rats graded to each degree of lipid deposition are shown in the next column. Data on lesions in the walls of coronary arteries are confined to those on vertical sections which were prepared from tissue blocks of the uppermost part of heart.

Aorta: The severities of the proliferative intimal thickening and the medial fatty lesion were examined and the results are presented in Table 6 . The figures in the table show the percentage of the Sudan III-positive area to the total areas of the intima and the first layer of media in the aortic wall. Although the degree of the proliferative intimal lesions varied remarkably with rats, there were no essential histological differences. The results of these observations are also presented schematically in Fig. 12.

TABLE 6. Fatty lesions of aortic intima and media

\begin{tabular}{|c|c|c|c|c|c|c|}
\hline Group & & Diet & $\begin{array}{l}\text { Number } \\
\text { of rats }\end{array}$ & Thoracic aorta & $\begin{array}{l}\text { Number } \\
\text { of rats }\end{array}$ & Abdominal aorta \\
\hline$I$ & High & casein, tap water & 7 & $1 \pm 2(\%)$ & 6 & $1 \pm 1(\%)$ \\
\hline II & High & casein, saline & 8 & $4 \pm 6$ & 6 & $1 \pm 2$ \\
\hline III & Low & casein, saline & 8 & $11 \pm 7$ & 5 & $8 \pm 2$ \\
\hline IV & Low & casein, saline, butter & 8 & $33 \pm 14$ & 7 & $10 \pm 8$ \\
\hline
\end{tabular}

Percentages of Sudan III-positive areas to total areas of intima and first layer of media were estimated in each rat and they were averaged for every dietary group. Data in the table are mean values and their standard deviations. 


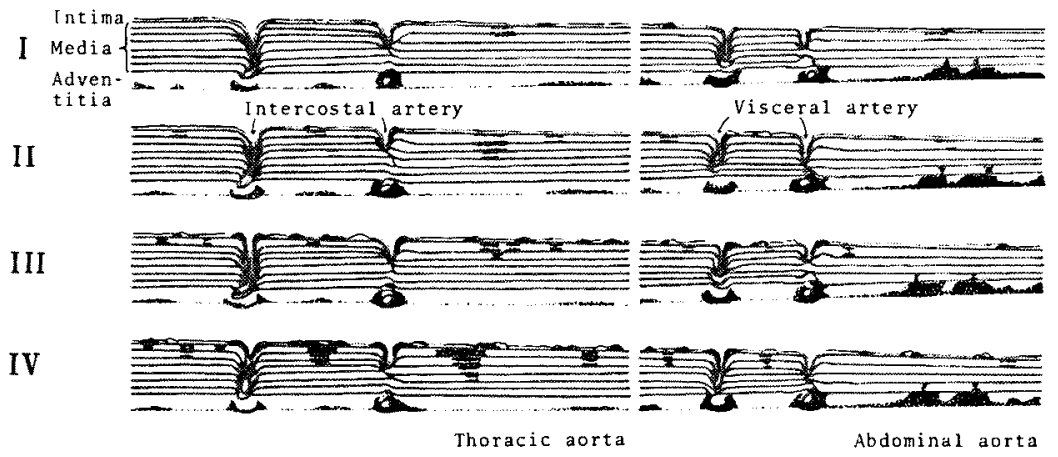

Fig. 12. Schematic representation of fatty lesions in rat aorta. Degrees of fatty lesions were averaged for every dietary group and presented schematically. Every horizontal line indicates elastic lamina. Swellings on intimal surface show proliferative lesions of intima and black areas represent sites which are positive to Sudan III. I; high casein, tap water. II; high casein, $1 \%$ saline. III; low casein, $1 \%$ saline. IV; low casein, $1 \%$ saline, butter.

As shown in Table 6 and Fig. 12, there was a good correlation between dietary casein levels and the fatty lesions of aortae. The atheromatous and lipomatous lesions were much less in the high casein rats. On the other hand, saline drinking and butter fat appeared to have accelerated the occurrence of lesions. These results coincided with the trend of serum cholesterol levels which were presented in Table 4. Therefore, the fatty lesion of aorta correlated more closely with the serum cholesterol level than that of the heart or kidneys.

\section{Discussion}

Growth of rats: Koyanagi and Matsuoka (1948) suggested previously that higher intake of fat makes the protein requirement increase. In the present experiment, the low casein rats gained considerably less weight than expected from the diet containing $11 \%$ casein. This may be caused by the deficiency of protein and aggravated with the large amount of dietary fat and cholesterol. Furthermore the hair loss appearing in the middle stage of the experiment was taken as one of the symptoms of protein deficiency. Renaud and Allard (1964) stated that similar hair loss is caused by a certain amino acid deficiency.

Cholesterol in serum and liver: There are many papers reporting the effect of quality and quantity of dietary protein on the concentration of serum cholesterol but their results are not consistent with one another. Some stated that the amount of dietary protein inversely correlated with the serum cholesterol level (Moyer et al. 1956) but others reported that the lowest serum cholesterol level was observed in the animals with the diet containing a certain range of protein (Jones and Huffman 1956). However, the reports on the experiments in which the diets comparable to those in the present experiment were employed show that the serum cholesterol level decreases remarkably with increasing dietary casein level (Moyer 
et al. 1956; Renaud and Allard 1964). When the serum cholesterol levels were heightened by feeding cholesterol and cholic acid, the protein requirement was probably increased for metabolizing the large amount of dietary fat and cholesterol.

Many papers reported that serum cholesterol levels of the sucrose-fed rats were higher than those of the starch-fed ones (Portman et a). 1956). However, the opposite results were also reported (Anderson 1969). As in the case of the dietary casein level, the effect of sucrose on serum and liver cholesterol levels in rats may be influenced by the experimental conditions. When the difference in casein contents in the high-fat and low-carbohydrate diet was compensated by cellulose, serum and liver cholesterol levels were also remarkably higher in the low casein rats (unpublished data). Thus, in the present experiment, it may be reasonable to assume that the differences in serum and liver cholesterol levels between the high and low casein rats are not due to the effect of dietary sucrose levels, but primarily to that of dietary casein levels.

Nishida et al. (1960 a) indicated that an increase of protein content in the diet induced an augmented degradation of cholesterol into bile acids in rat liver and also suppressed the biosynthesis of cholesterol in birds (Nishida et al. $1960 \mathrm{~b}$ ). Renaud (1966) suggested that the lowering effect of dietary casein on serum cholesterol level was probably due to its methionine content.

It is reported that the high salt diet induces hypertension and also elevates the concentration of serum cholesterol in rats (Koyanagi et al. 1959; Hilker et al. 1965). In the present experiment, both the serum and liver cholesterol levels were apparently increased by the ad libitum administration of $1 \%$ saline. It is probable that the intake of excessive sodium chloride suppresses the catabolism of cholesterol in rats by some mechanisms.

The cholesterol levels in serum and livers of rats treated with the butter fat diet in group IV were higher than those of rats in group III which were fed the hydrogenated oil diet. As seen in Table 2, the saturated fatty acid content in the hydrogenated oil mixture differs from that of butter fat, and also it is clear that the fatty acid composition of both dietary fats differs from each other. In the present experiment, however, it is reasonable to consider that the high levels of serum and liver cholesterol of the butter fat rats were due to their much larger diet intake than that of the hydrogenated oil rats (Table 3 ).

Histological changes of the heart, aorta and kidneys: In the present experiment, proliferative thickening of intima occurred in the small coronary arteries but no lesion was observed in the intima of renal small arteries. The lipid deposition in the media of renal small arteries was found without exception along the external lamina. Since the external lamina is absent in the coronary arteries, the difference in the histological changes induced in both arteries is interesting in connection with the structure of each artery. The lesions found in small coronary arteries were limited to those in the left ventricular wall and interventricular septum, and scarcely any lesions were noted in the right ventricular wall. Recently Wilson 
et al. $(1970,1971)$ reported similar observations.

Hollander (1968) reported that the occurrence of cartilaginous tissue in the heart of rats was regularly seen and ascribed to mechanical forces at this site. On the other hand, it is well known that the calcification occurs with advancing age in the cardiac cartilaginous tissues of animals such as horses and swines. In the present experiment, the lipid deposition in the cartilaginous tissue was observed in nearly all the animals in every experimental group and interpreted as indicating the susceptibility of the tissue to any morphological changes.

The histological changes seen in aorta may not be identical with those of human atherosclerosis. However, the swelling and thickening of intima, proliferative stratification and degeneration of intimal cell and severe lipid deposition in intima and media were all considered similar to those reported on the experimental atherosclerosis in rats. The atheromatous lesions in aortae were supposed, judging from the size of plaques, to be those of the initial stage. No typical foam cell or fibrillar material was recognized in the plaques.

Lipid deposition in media was seen widely in every group and highly correlated with the level of serum cholesterol. Up to the present, the occurrence of lipid deposition in aortic media has not been adequately emphasized. In the present experiment, the deformation of muscle cells and the rupture of elastic laminae were clearly recognized at the area of lipid deposition. Thus, the lipid deposition in aortic media is considered to be one of the remarkable changes of aorta.

The low casein rats showed more than twice as high serum cholesterol levels as those of the high casein rats, and they also exhibited remarkably severe fatty lesions of the coronary arteries, renal small arteries and renal glomeruli. When analyzed in detail, however, the severity of the fatty lesions in the organs was not necessarily in simple correlation with the serum cholesterol levels. In connection with this, the following three points were specifically noted. Firstly, fatty lesions of the coronary arteries, renal small arteries and renal glomeruli were milder in the butter fat rats in group IV than those of the hydrogenated oil rats in group III although the serum cholesterol level of the former was rather higher than that of the latter. Secondly, fatty lesions of aorta in group IV rats were remarkably severer than those of group III rats in spite of the slight difference in the serum cholesterol levels between both groups. Finally, there was generally a rather large individual fluctuation in the biochemical results and histological findings of the rats.

Up to now highly unsaturated oils such as corn and peanut oils have been used as a fat source of the atherogenic diet as well as saturated fats such as lard and butter fat. These highly unsaturated oils are said to affect the arterial wall differently from saturated fat (Gresham and Howard 1960; Scott et al. 1964). In the present experiment, however, there was no essential difference in the effect of butter fat and the hydrogenated oil on the property of several histological changes. This probably resulted from the fact that the content of highly unsaturated fatty acids in the hydrogenated oil mixture was very low in comparison with that of 
corn oil or peanut oil and it was similar to that of butter fat. Furthermore it is probable that the relatively short duration of the experiment did not allow definite histological difference to develop between two dietary fat groups.

The hydrogenated oil rats showed severer histological changes in the heart and kidneys in comparison with the butter fat animals although the serum cholesterol level of the former was somewhat lower than that of the latter. At our present knowledge, it is difficult to state possible explanations on these findings.

It was already reported by Belliveau and Marsh (1961) that the degree of lipid deposition in the aortae of rats on a high-fat atherogenic diet significantly increased when these rats were given $1 \%$ saline in place of tap water. In the present experiment, the aggravating effect of saline administration was seen not only on the lipid deposition in the aortic wall but also on the severity of fatty lesions of the small arteries in the heart and kidneys and of cardiac muscles.

In the present experiment, no infarction was found in the heart or kidneys although the production of infarcts had been reported frequently in similar experiments. It is conceivable that this discrepancy is due to the diet which contains no propylthiouracil or to the short-term experiment of 16 weeks.

\section{Acknowledgment}

I wish to express my sincere gratitude to Prof. Kan'ichi Yagawa, Department of Pathology I, School of Medicine, and Prof. Takeshi Kimura, Department of Internal Medicine II, School of Medicine, for their constant guidance and encouragement; to Prof. Mitsuo Rikimaru, School of Liberal Arts and Sciences, for providing every convenience in the accomplishment of the experiment.

I am also indebted to Miss Mitsuko Takahashi for her interest and technical help.

\section{References}

1) Anderson, T.A. (1969) Effect of carbohydrate source on serum and hepatic cholesterol levels in the cholesterol-fed rat. Proc. Soc. exp. Biol. Med., 130, 884-887.

2) Belliveau, R. \& Marsh, M.E. (1961) Effects of sodium chloride in rats fed an atherogenic diet. Arch. Path., 71, 559-565.

3) Folch, J., Lees, M. \& Sloane Stanley, G.H. (1957) A simple method for the isolation and purification of total lipids from animal tissues. $J$. biol. Chem., 226, 497-509.

4) Gresham, G.A. \& Howard, A.N. (1960) The independent production of atherosclerosis and thrombosis in the rat. Brit. J. exp. Path., 41, 395-402.

5) Handbook of Oil and Fat Chemistry (Jap.) (1969) 4th ed., edited by Japanese Society of Oil and Fat Chemist. Maruzen, Tokyo, p. 341.

6) Hartroft, W.S., Ridout, J.H., Sellers, E.A. \& Best, C.H. (1952) Atheromatous changes in aorta, carotid and coronary arteries of choline-deficient rats. Proc. Soc. exp. Biol. Med., 81, 384-393.

7) Hilker, D.M., Wenkam, N.S. \& Lichton, I.J. (1965) Blood pressure elevation and renal pathology in rats fed simulated Japanese diets. $J$. Nutr., 87, 371-384.

8) Hollander, C.F. (1968) Cartilaginous focus at the base of the non-coronary semilunar valve of the aorta in rats of different ages. Exp. Geront., 3, 303-307.

9) Jones, R.J. \& Huffman, S. (1956) Chronic effect of dietary protein on hypercholesteremia in the rat. Proc. Soc. exp. Biol. Med., 93, 519-522.

10) Koyanagi, T. \& Matsuoka, M. (1948) Studies on the physiological actions of vitamin $\mathrm{B}_{2}$. Part 6 Relationship between the kinds of dietary fat and the vitamin $\mathbf{B}_{2}$ content in rat urine. Igaku to Seibutsugaku (Jap.), 13, 258-260. 
11) Koyanagi, T., Hareyama, S. \& Ota, M. (1959) The effect of riboflavin on hypertension induced by high salt diet in the rat. Bull. Agr. Chem. Soc. Japan, 23, 3-6.

12) Kritchevsky, D. (1962) Cholesterol and atherosclerosis. Amer. J. clin. Nutr., 10, 269-276.

13) Moyer, A.M., Kritchersky, D., Logan, J.B. \& Cox, H.R. (1956) Dietary protein and serum cholesterol in rats. Proc. Soc. exp. Biol. Med., 92, 736-737.

14) Nakadate, K., Takahashi, M. \& Yagawa, K. (1973) Preparing the vertical histological sections of the rat aorta rolled up in a sheath of macaroni. Arch. histol. jap., 35, 127-132.

15) Nishida, T., Ueno, A. \& Kummerow, F.A. (1960 a) Metabolism of cholesterol-4-C ${ }^{14}$ in bile duct cannulated chicks and rats. Circulat. Res., 8, 742-748.

16) Nishida, T., Ueno, A. \& Kummerow, F.A. (1960 b) Effect of dietary protein on the metabolism of sodium acetate-1- $\mathrm{C}^{14}$ in chicks. $J$. Nutr., 71, 379-386.

17) Portman, O.W., Lawry, E.Y. \& Bruno, D. (1956) Effect of dietary carbohydrate on experimentally induced hypercholesteremia and hyperbetalipoproteinemia in rats. Proc. Soc. exp. Biol. Med., 91, 321-323.

18) Renaud, S. (1966) Prevention by methionine feeding of atherosclerosis and thrombosis in hyperlipemic rats. Proc. Soc. exp. Biol. Med., 121, 452-455.

19) Renaud, S. \& Allard, C. (1964) Effect of dietary protein level on cholesterolemia, thrombosis, atherosclerosis and hypertension in the rat. J. Nutr., 83, 149-156.

20) Scott, R.F., Morrison, E.S., Thomas, W.A., Jones, R. \& Nam, S.C. (1964) Shortterm feeding of unsaturated versus saturated fat in the production of atherosclerosis in the rat. Exp. molec. Path., 3, 421-443.

21) Shibata, S. \& Sasaki, M. (1967) Quantitative Ultramicroanalysis in Clinical Chemistry (Jap.), 2nd ed., Kinpodo, Kyoto, p. 134.

22) Thomas, W.A. \& Hartroft, W.S. (1959) Myocardial infarction in rats fed diets containing high fat, cholesterol, thiouracil, and sodium cholate. Circulation, 19, $65-72$.

23) Thomas, W.A., Hartroft, W.S. \& O'Neal, R.M. (1959) Modifications of diets responsible for induction of coronary thromboses and myocardial infarcts in rats. J. Nutr., 69, 325-337.

24) Wilson, R.B. \& Hartroft, W.S. (1970) Pathogenesis of myocardial infarcts in rats fed a thrombogenic diet. Arch. Path., 89, 457-469.

25) Wilson, R.B., Hartroft, W.S., Conen, P.E., Anderson, D.E. \& Newberne, P.M. (1971) Early changes in myocardium of rats fed an infaret-producing diet. Arch. Path., 91, 307-317.

26) Wissler, R.W., Eilert, M.L., Schroeder, M.A. \& Cohen, L. (1954) Production of lipomatous and atheromatous arterial lesions in the albino rat. Arch. Path., 57, 333351. 